\title{
A tradução no Brasil e a retradução de clássicos: algumas considerações
}

\section{Translation in Brazil and the retranslation of classics: a few considerations}

\author{
Marcia A. P. Martins*
}

Resumo: A proposta deste artigo é enfocar a condição do Brasil como cultura tradutora, com um segmento de títulos traduzidos cuja robustez muito se deve às inúmeras retraduções de clássicos. São reescritas simultâneas ou sucessivas que derivam de motivações variadas - textuais, ideológicas, políticas, estéticas, epistemológicas - e recorrem a diferentes estratégias tradutórias para concretizar os objetivos de seus promotores e atender às expectativas do público a que se destinam. Para exemplificar a fecundidade dessa prática, será abordada, a partir de uma visão panorâmica, a trajetória em português do Brasil de um autor específico, presença certa nos cânones literários formados ao menos no Ocidente: William Shakespeare, cuja obra dramática é objeto de traduções, retraduções e adaptações para o português do Brasil desde o século XIX.

Palavras-chave: Retraduções; Sociologia da tradução; Obras clássicas; Shakespeare em tradução no Brasil

Abstract: The purpose of this article is to focus on Brazil's status as a translating culture, with a significant repertoire of translated titles due to a great number of retranslations of classical works. There can be concurrent rewritings originating from diverse motivations - textual, ideological, political, aesthetical, epistemological and that adhere to distinct translation strategies to achieve their promoters' goals as well as to meet the receiving audience's expectations. To illustrate how fertile this practice is, the trajectory in Brazilian Portuguese of an individual writer who is ubiquitous in every Western literary canon will be singled out: William Shakespeare, whose dramatic oeuvre has been translated, retranslated and adapted in Brazil since the 19 th century.

\footnotetext{
* Pontifícia Universidade Católica do Rio de Janeiro (PUC-Rio)
} 
Keywords: Retranslations; Sociology of Translation; Classical works; Shakespeare in translation in Brazil.

\section{O Brasil como cultura tradutora}

A tradução é um dos principais meios de consagração de autores, obras e gêneros, como bem formulou Pascale Casanova (2010). André Lefevere (1992) a considera o tipo mais influente de reescrita, conceito que abrange diferentes práticas que detêm o poder de criar imagens de autores e obras, imagens essas resultantes não só de gestos interpretativos como também de opções linguísticas e estilísticas. Diante do papel fecundante da literatura traduzida em relação ao sistema literário que a recebe, Itamar Even-Zohar, ao desenvolver o modelo polissistêmico, nos anos 1970, postulou que o conjunto de obras traduzidas de um dado polissistema literário formaria, assim, um sistema próprio, o sistema de literatura traduzida (1990). Ampliando o escopo da proposta de Even-Zohar, podemos entender que os demais cossistemas igualmente subsumidos no sistema cultural, tais como o religioso, o político, o econômico, o jurídico, também contêm seus sistemas próprios de textos traduzidos. Nas culturas eminentemente tradutoras, como é o Brasil, o sistema de literatura traduzida tende naturalmente a ser muito robusto e variado, muitas vezes contemplando gêneros e temas que preenchem lacunas no repertório literário nacional, além de oferecer maior diversidade para os leitores.

Com base no conceito bourdieusiano de capital como prestígio acumulado, seja econômico, social ou cultural (BOURDIEU 1986), e na perspectiva de Casanova (2010), que identifica as línguas na esfera literária como dominantes e dominadas, vemos que há muita desigualdade e luta pelo poder nas trocas literárias na assim denominada "República Mundial das Letras" (CASANOVA 2002). Inclusive, precisamente para sublinhar esses dois fatores, em sua teorização Casanova opta por se referir às línguas como "dominantes" e "dominadas", em vez classificá-las espacialmente como "centrais" e "periféricas". Enquanto as línguas dominantes detêm considerável capital literário, em parte devido ao grande número de textos considerados 
"universais" que foram originalmente escritos nesses vernáculos, as dominadas possuem baixo capital literário e se subdividem em quatro subgrupos: o de línguas ágrafas, que não podem se beneficiar da tradução no universo literário mundial; o de línguas jovens, recriadas ou recém-criadas no contexto de movimentos separatistas; o de línguas nacionais de países pequenos, com poucos falantes; e o de línguas que, apesar de terem um número expressivo de falantes e tradições literárias importantes, não são valorizadas no cenário literário mundial ${ }^{1}$ (2010: 289-90). A língua portuguesa, pelo menos nas variedades brasileira e europeia, parece encaixar-se nesse último subgrupo identificado por Casanova, gerando um movimento bastante forte de importação, por meio de traduções, do que é produzido no universo não só das línguas dominantes, em um esforço de acumulação de capital, mas também de outras línguas dominadas.

No que se refere ao Brasil e à variedade da língua portuguesa aqui falada, a centralidade da tradução é inequívoca, apesar de eventuais oscilações em termos de intensidade do movimento tradutório. Há 15 anos teve início uma pesquisa intitulada Produção e Vendas do Setor Editorial Brasileiro, disponível no portal do Sindicato Nacional dos Editores de Livros (SNEL, 2020), destinada a mapear anualmente a performance do setor editorial e de seus quatro subsetores: Didáticos; Científicos, Técnicos e Profissionais (CTP); Obras Gerais; e Religiosos. O levantamento é realizado pela Fundação Instituto de Pesquisas Econômicas (Fipe) - entidade ligada à USP - por encomenda do Sindicato Nacional dos Editores de Livros e da Câmara Brasileira do Livro. Segundo os dados da Fipe, nos últimos quatro anos com pesquisa divulgada, 2016 a 2019, considerando apenas os títulos com novos números de ISBN, os livros traduzidos responderam por cerca de 40\% da produção editorial, em relação aos autores nacionais (CBL c2016).

\footnotetext{
${ }^{1}$ Casanova cita como exemplo o árabe, o hindi e o chinês.
} 
Gráfico 1 - Participação percentual - autores nacionais x títulos traduzidos (2016-2019)

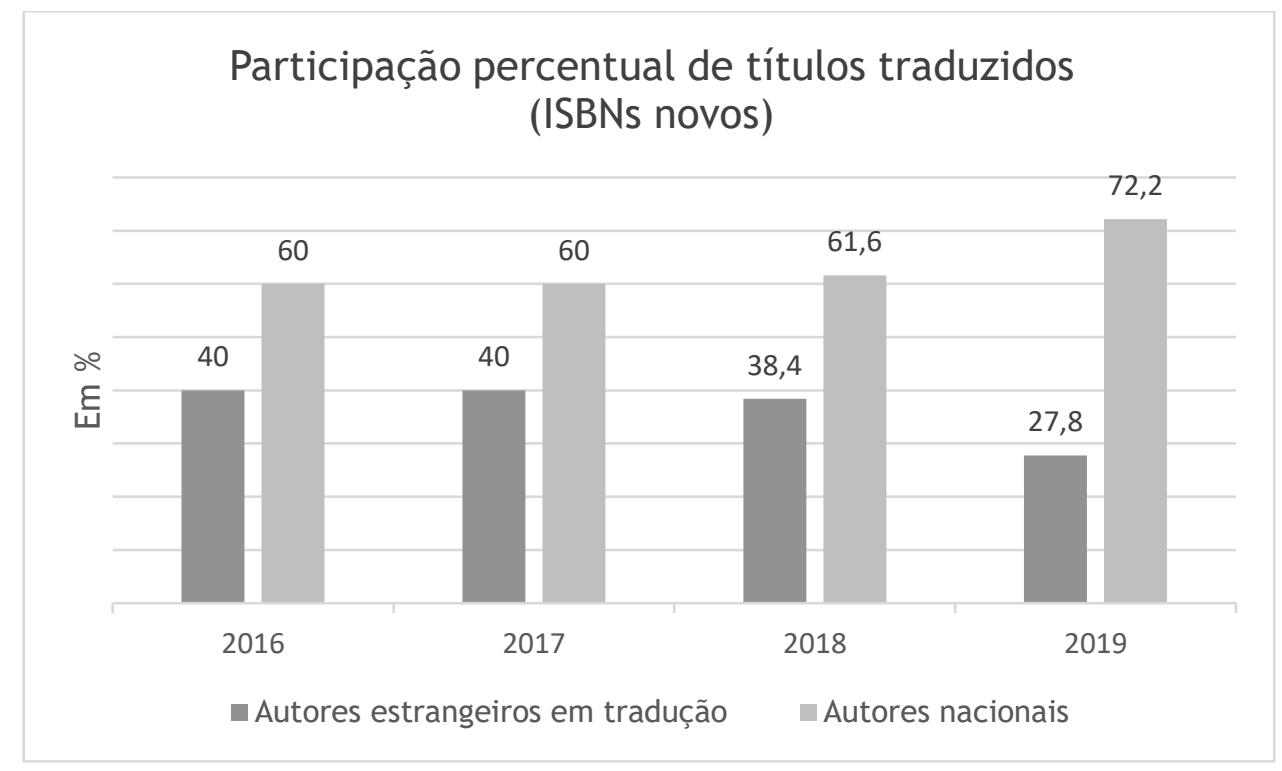

Fonte: Adaptado das pesquisas Fipe (CBL c2016)

Essa pesquisa vem apresentando uma variação grande de métricas e parâmetros, por isso não foi possível estabelecer uma série histórica completa. $\mathrm{Na}$ primeira fase da pesquisa, de 2005 a 2015, consideravam-se também as reedições e reimpressões de todos os títulos editados, quer de autores nacionais, quer traduzidos, conforme representado no gráfico abaixo (CBL c2016).

Gráfico 2 - Participação percentual de títulos traduzidos (2005-2014) 


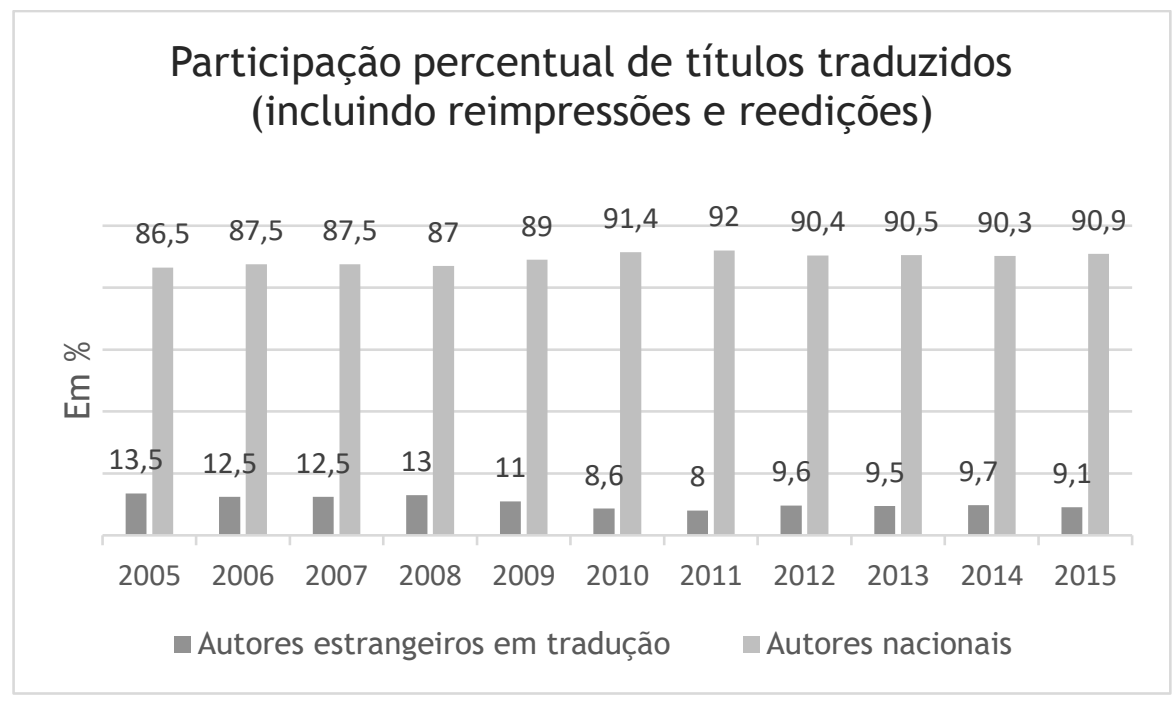

Fonte: Adaptado das pesquisas Fipe (CBL c2016)

De acordo com essa metodologia, a participação dos livros traduzidos no cômputo total oscilou na faixa de $13,5 \%$ a $8 \%$, ou seja, resultados bastante diferentes dos últimos quatro anos, mas explicados em parte pelo fato de que o número de reedições e reimpressões de autores nacionais, levando-se em conta os quatro subsetores, é proporcionalmente maior ao de títulos traduzidos.

O relatório Produção e Vendas do Setor Editorial Brasileiro de 2009, ao fazer a análise dos dados referentes a obras traduzidas e a obras de autores nacionais, chama a atenção para a "pouca participação dos títulos traduzidos nos exemplares totais produzidos, tanto em 2008 quanto em 2009 (6,1 e 7,3\% respectivamente)" (FIPE 2010). Considero, no entanto, ser necessário examinar esses dados a partir de uma outra perspectiva. A proporção das traduções aumentou significativamente com a mudança de cálculo a partir de 2016, passando a considerar apenas os ISBNs novos, como observado acima. A possível distorção provocada por essa diferença no modo de calcular a participação percentual das traduções tende a se acentuar em virtude do peso dos livros didáticos, que de um lado são muito reeditados e/ou reimpressos e, de outro, quase não são traduzidos, como o próprio relatório ressalta: "A explicação disso [a alegada baixa participação das traduções na produção editorial anual] está no grande peso que tem o subsetor Didáticos, no qual contam-se muito poucos títulos traduzidos" (FIPE 2010). 
Contrastando com o diagnóstico da pesquisa da Fipe está a ideia muito difundida nas últimas décadas de que " $80 \%$ dos livros de prosa, poesia e referência, bem como manuais e catálogos, são traduzidos" (WYLER 2003: 13). Os dados, contudo, mostram proporções bem menores, mas ainda assim superiores às estatísticas referentes, por exemplo, aos mercados editoriais britânico e estadunidense, onde a participação dos títulos traduzidos na produção editorial anual tem consistentemente ficado entre 2 e 4\% (VENUTI 2008 e 2016; DIMENT 2019), com viés de queda desde meados da década de 1990 (VENUTI 2008:11).

É diante desse quadro que podemos considerar o Brasil uma cultura tradutora, avaliação que se respalda nas considerações de Venuti (2008: 11) a respeito das práticas editoriais internacionais. Segundo o teórico, a indústria editorial registrou uma grande expansão nas últimas décadas, com as traduções sempre representando um percentual da produção total de livros por ele considerado elevado, como no caso da França, onde a participação dos títulos traduzidos tem oscilado entre 8 e 12\% do total de publicações (2008: 11).

Examinando-se as tabelas 1 e 2 acima, mesmo com dados produzidos a partir de métricas distintas, nota-se um viés de queda na participação das traduções na produção editorial brasileira. Para entendê-lo e explicá-lo adequadamente, seria necessário dispor de mais dados, inclusive de outras fontes, e compatibilizar as metodologias, mas algumas possíveis causas podem ser aventadas. Uma delas é a mudança na política de publicação adotada por algumas editoras majors, que até a crise econômica de 2015, cujo impacto se fez sentir nos mais diferentes segmentos de mercado, costumavam dar muito espaço ao livro estrangeiro, considerado um produto que já vinha pronto e testado, dependendo apenas de tradução. 0 best-seller estrangeiro, por exemplo, costumava ser lançado com tiragens bem maiores do que as de autores literários nacionais. A partir de 2015 - lembrando que estamos falando de algumas editoras, sem generalizar - o custo de publicar literatura estrangeira cresceu muito, diante da valorização do dólar e dos adiantamentos caros que essas compras exigem. A consequência foi uma ênfase em autores nacionais e na publicação de menos títulos por ano, em tiragens maiores e investindo mais em marketing. Uma outra possível causa é o surgimento de 
muitos autores nacionais consagrados nas redes sociais, os chamados influenciadores, que têm público cativo e garantem grandes patamares de vendas e tiragens elevadas. Esses fatores, bem como outros que necessitam de uma pesquisa aprofundada para serem identificados, podem estar contribuindo para a atual redução - ainda pequena - na proporção de títulos traduzidos no total anual editado.

Em relação às línguas-fonte das traduções, o inglês se destaca, como já esperado. Segundo dados referentes ao período de 2005 a 2009, os únicos disponíveis na pesquisa anual da Fipe (CBL c2016), em média 62\% de todos os títulos traduzidos para o português do Brasil se originaram de textos em língua inglesa. A proporção de textos-fonte em inglês nas traduções brasileiras foi entre cinco e seis vezes maior do que a segunda língua mais traduzida, quase sempre o espanhol, como demonstra a tabela a seguir, que apresenta a participação percentual das três principais línguas originárias no total de títulos editados e exemplares traduzidos (voltando a lembrar que reedições e reimpressões estão incluídas).

Tabela 1 - Línguas-fonte das obras traduzidas - participação percentual no total de títulos editados e exemplares traduzidos² ${ }^{2}$ (2005-2009)

\begin{tabular}{|c|c|c|c|c|}
\hline Ano & $\begin{array}{c}\text { Total de } \\
\text { títulos }\end{array}$ & Inglês & Espanhol & Francês \\
\hline 2005 & 5.608 & $63,7 \%$ & $10,2 \%$ & $9,1 \%$ \\
\hline 2006 & 5.830 & $64,3 \%$ & $12,8 \%$ & $7,8 \%$ \\
\hline 2007 & 5.586 & $61,4 \%$ & $12,9 \%$ & $7 \%$ \\
\hline 2008 & 6.626 & $60 \%$ & $16 \%$ & $11,3 \%$ \\
\hline 2009 & 5.807 & $63,7 \%$ & $10,6 \%$ & $11,6 \%$ \\
\hline
\end{tabular}

Fonte: Adaptada das pesquisas Fipe (CBL c2016)

A posição que o inglês ocupa no Brasil, como a língua mais traduzida, se repete no resto do mundo, com a diferença que, globalmente, é seguido pelo francês e pelo alemão, em proporções muito menores, segundo a base de dados

\footnotetext{
${ }^{2}$ Foi usada apenas uma casa decimal, tendo os valores sido aproximados para mais ou para menos.
} 
do Index Translationum (AQUINO, 2017) ${ }^{3}$. O predomínio do inglês como línguafonte é corroborado por Venuti, ao citar o caso da Europa Ocidental, onde as traduções de obras estrangeiras - que têm uma participação elevada na produção editorial anual, como já mencionado - são dominadas por títulos publicados originalmente em língua inglesa, quadro este que perdura desde a Segunda Grande Guerra (2008: 11).

\section{Sobre retradução}

Num quadro, portanto, de intensa atividade tradutória, a presença dos clássicos se destaca no Brasil, inspirando incessantes retraduções, instigadas pelas motivações mais diversas por parte de tradutores/as e editoras, como será discutido um pouco mais adiante. Antes, porém, cabem algumas considerações a respeito do conceito de retradução.

O senso comum entende retradução como toda nova tradução de um texto já traduzido numa dada língua, definição que Antoine Berman subscreve e, ao mesmo tempo, expande. Em seu artigo "A retradução como espaço da tradução" (2017), publicado originalmente em Palimpsestes, em 1990, Berman problematiza o estatuto da tradução da obra de um autor que tenha sido apenas parcial ou indireta, ou seja, produzida a partir de uma tradução anterior, dando o exemplo da transposição da obra de Plutarco para a língua francesa por Jacques Amyot. Diz o teórico e tradutor que Plutarco,

mesmo já tendo sido traduzido em francês, o foi apenas parcialmente e, via de regra, a partir do latim ou do italiano. Amyot de certa maneira fez uma primeira tradução de Plutarco. Primeira em relação aos outros textos, dentre eles, alguns que não tinham sido traduzidos, primeira em relação à língua de partida, o grego. Apesar disso, podemos falar aqui de retradução, já que há uma nova tradução de uma obra, mesmo se uma parte da obra ainda não tivesse sido traduzida. Basta que um texto de um autor já tenha sido traduzido para que a tradução dos outros textos deste autor entre no espaço da retradução. (BERMAN 2017: 264)

\footnotetext{
${ }^{3}$ A página do Index Translationum está em manutenção desde o início da elaboração deste trabalho, não tendo sido possível consultar as estatísticas diretamente. No início de 2020, o português ocupava o $18^{\circ}$ lugar no ranking das línguas mais traduzidas.
} 
Para Berman, retraduzir é um gesto necessário porque as traduções envelhecem e porque nenhuma é a tradução; "traduzir é uma atividade submetida ao tempo" e "que tem uma temporalidade própria: a da caducidade e do inacabamento" (2017: 262). Trata-se, a seu ver, de um "fenômeno misterioso":

enquanto os originais permanecem eternamente jovens (não importando o grau de interesse que se tenha por eles, sua proximidade ou seu distanciamento cultural), as traduções "envelhecem". Correspondendo a um estado determinado da língua, da literatura, da cultura, acontece que, muitas vezes de maneira bem rápida, elas não respondem mais ao estado seguinte. É preciso então retraduzir, pois a tradução existente não desempenha mais o papel de revelação e de comunicação das obras. (BERMAn 2017: 262)

Há, no entanto, exceções, para quem "a História nos mostra que existem traduções que perduram tanto quanto os originais e que, às vezes, têm mais brilho que estes" (BERMAN 2017: 262). Essas são as grandes traduções, que não envelhecem, que são "inigualáveis", por uma série de razões elencadas pelo teórico francês, dentre elas o traço comum de serem todas novas traduções de um texto originário já traduzido anteriormente. E o princípio gerador de tal fenômeno é a premissa de que toda tradução é insuficiente, ou seja, é marcada pela "não-tradução". As primeiras traduções são aquelas mais tocadas pela nãotradução (BERMAN 2017: 265), em que a insuficiência que afeta qualquer ato de tradução - insuficiência essa que consiste simultaneamente na incapacidade de traduzir e na resistência ao traduzir - está em seu máximo. É a necessidade de reduzir a insuficiência original que, para Berman, leva a um ato de retradução, que, se bem-sucedido, produz uma grande tradução, em que "a insuficiência continua presente, mas contrabalanceada por um fenômeno que podemos chamar, com os tradutores do século XVI, a cópia, a abundância" (BERMAn 2017: 266), personificada, por exemplo, pela riqueza da língua, da relação com a língua do original, riqueza textual, riqueza significante.

As reflexões de Berman oferecem, portanto, um contra-argumento importante para se contestar o tradicional e melancólico discurso da perda, que é a perspectiva da abundância, condição que vai sendo alcançada por meio de sucessivas retraduções, e que tem o efeito de justificar e valorizar as novas traduções. 
0 impulso de retraduzir é bastante frequente nas mais diferentes culturas, tendo como um dos seus objetos preferenciais as obras canonizadas e decorrendo de motivações várias, como as elencadas a seguir, algumas delas também discutidas por Venuti em seu ensaio sobre retradução (2013):

(a) atualizar uma tradução antiga que seguiu normas tradutórias, linguísticas e/ou editoriais consideradas ultrapassadas, como é o caso do tratamento dos diálogos ficcionais nas traduções, hoje tendendo muito mais ao coloquialismo do que até o final do século XX;

(b) promover uma tradução direta quando as que estão disponíveis se derivam de um texto-fonte que já é uma tradução, ou então realizar a tradução a partir de um texto fonte alternativo, no caso de obras com mais de um texto "autorizado", que competem entre si sobre qual é o mais autêntico. Esse é o caso de algumas peças de Shakespeare, como Hamlet, Otelo e Rei Lear;

(c) atribuir novos sentidos a uma dada obra a partir da exegese mais recente, ou então ressignificá-la diante de circunstâncias específicas, como a agenda do movimento feminista, em suas sucessivas ondas;

(d) atender ao desejo de algum/a tradutor/a ou estudioso/a que queira contribuir com sua própria versão de um clássico, ansioso/a por nele inscrever a sua interpretação ou destacar valores estéticos que identifica no texto originário;

(e) explicitar a topicalidade de uma obra com alguma situação presente, como retraduzir 1984 de Orwell num contexto político de forte tendência autoritária;

(f) capitalizar o destaque circunstancial de um dado autor ou obra, como no óbvio exemplo do lançamento de uma adaptação de um texto para o cinema, ou para uma novela televisiva, como é comum no Brasil. Nesses casos, a retradução costuma visar mais um retorno econômico do que um valor literário ou acadêmico;

(g) alcançar o objetivo muitas vezes declarado de substituir traduções anteriores consideradas falhas ou "ruins". Este foi o intuito do diplomata Geraldo Silos, um apaixonado pelo drama shakespeariano que durante quatro anos, no início da década de 1980 , se dedicou ao projeto de 
traduzir Hamlet, desafiado por um amigo durante um encontro em que se comentava a má qualidade das traduções dessa peça;

(h) no caso das editoras, aproveitar que um autor caiu ou já está em domínio público para oferecer suas obras em catálogo. 0 estatuto de obra canonizada agrega prestígio à editora e garante uma demanda de mercado, mesmo que em um ritmo menos intenso do que best-sellers ocasionais. A dispensa do pagamento de direitos autorais torna, é claro, a publicação mais barata. Além disso, também ficam liberadas as adaptações mais diversas, o que propicia grandes desafios estéticos e oportunidades comerciais.

Uma característica comum das retraduções é a presença de paratextos, que criam uma dimensão intertextual para o texto traduzido, estabelecendo uma rede de relações que envolve, de um lado, o texto e o contexto de origem, e de outro, o contexto de recepção em vários momentos de um eixo diacrônico. Essa rede de relações também se estende a outros textos, além dos de partida e de chegada, produzidos nos dois contextos (VENUTI 2013: 98). Os paratextos podem ser linguísticos, incluindo prefácios, posfácios, notas e comentários do próprio tradutor ou de especialistas, bem como material promocional da editora, ou ainda imagéticos, como capas novas, frequentemente ilustradas com cenas e atores de uma adaptação intermidiática recente. Esse aparato paratextual sinaliza o caráter de retradução do texto publicado e, muitas vezes, explicita a diferença entre a nova versão e as anteriores, ou mesmo a motivação do tradutor ou da editora para produzi-la.

Textos canonizados, de autoridade cultural, como a Bíblia, os épicos homéricos, a Divina Comédia, as peças de Shakespeare, Dom Quixote, são um convite às retraduções, como assinala Venuti (2013), pelo fato de que as diferentes comunidades de leitores da cultura receptora vão procurar interpretá-los de acordo com seus próprios valores. Em consequência, essas retraduções adotarão diferentes estratégias tradutórias, que nelas inscreverão interpretações distintas, ou até mesmo conflitantes (VENUTI 2013: 96-97). Dessa forma, argumenta ele, uma retradução pode tanto refletir mudanças nos valores e instituições da cultura tradutora, como provocar mudanças, ao 
inspirar novas formas de ler e apreciar os textos de origem (VENUTI 2013: 107). No caso dos clássicos literários, as expectativas de comunidades de leitores podem ser bastante variadas, inclusive pelo fato de haver considerável massa crítica sobre eles. Isso já cria, aprioristicamente, imagens da obra e do autor que poderão ser reforçadas ou não após a leitura. Lembrando Calvino, "Os clássicos são aqueles livros que chegam até nós trazendo consigo as marcas das leituras que precederam a nossa e atrás de si os traços que deixaram na cultura ou culturas que atravessaram" (1993: 11).

Por fim, vale observar que as retraduções e a formação de cânones literários são mutuamente dependentes: as múltiplas traduções ajudam os textos a alcançar o estatuto de um clássico, e por sua vez tal estatuto estimula a produção de novas traduções (KoSkINEN; PALOPOSKI 2010: 295), como vem acontecendo com a obra shakespeariana em termos globais. As diferentes modalidades de reescrita dessa obra podem incluir as tradicionais traduções inter- e intralinguais, bem como as transposições intersemióticas e intermidiáticas, como para cinema, ópera, balé, peças musicais (como sinfonias, scherzos e até heavy metal ${ }^{4}$ ), linguagem dos sinais, games, mangás, webcomics, Tweeter, mensagens de WhatsApp e poesia de cordel.

\section{O caso das (re)traduções brasileiras do teatro shakespeariano}

As retraduções literárias têm sido objeto de incontáveis pesquisas, frequentemente sob a forma de estudos de caso que enfocam traduções de textos clássicos. Shakespeare é o clássico por excelência, até porque sua produção quase não tem paralelo com a de muitos outros autores canonizados: é autor de 154 sonetos, 4 poemas, três deles narrativos, e agora 39 peças, com a recente inclusão no seu teatro completo de dois textos escritos em colaboração, Edward III (Eduardo III), com Thomas Kyd, e The Two Noble

\footnotetext{
${ }^{4} \mathrm{~A}$ banda brasileira de heavy metal Angra produziu um álbum conceitual intitulado Aqua (2010), que gira em torno da peça A Tempestade de William Shakespeare.
} 
Kinsmen (Os dois primos nobres, ou Os dois nobres parentes), com John Fletcher.

O caso das traduções e retraduções do teatro de Shakespeare no Brasil é emblemático. A primeira tradução integral de uma peça shakespeariana, feita para o nosso português a partir de um original em língua inglesa e publicada em forma de livro, foi o Hamlet do poeta e jurista Tristão da Cunha, datado de 1933. Até hoje, Hamlet é a peça do autor mais traduzida no Brasil, com 16 traduções integrais publicadas. Desde esse Hamlet, as peças de Shakespeare começaram a ser traduzidas na íntegra por poetas, escritores, estudiosos e tradutores profissionais, agora a partir de originais em inglês, totalizando até hoje 218 traduções diferentes do cânone dramático, havendo várias outras em preparação. ${ }^{5}$ As características que as distinguem e singularizam, algumas delas elencadas abaixo, já são justificativa suficiente para a existência de retraduções:

(a) Há traduções que seguem a combinação shakespeariana de versos brancos, versos rimados e prosa, enquanto outras optam pela prosa do início ao fim, ressalvando às vezes as canções. Para dar uma ideia do equilíbrio entre as duas estratégias, do total de traduções em português do Brasil publicadas até o momento, 114 são em prosa e verso (53\%) e 100 (47\%), integralmente em prosa. Adotam a primeira estratégia tradutores como Barbara Heliodora, José Roberto O'Shea e Aíla de Oliveira Gomes; já a segunda é seguida, por exemplo, por Elvio Funck, Millôr Fernandes e Beatriz Viégas-Faria.

(b) Entre aquelas que optam por manter os versos, a diferença é o tratamento do pentâmetro iâmbico shakespeariano, o verso tradicional de cinco pés com acento nas sílabas pares. Alguns tradutores consideram que o correspondente natural dessa métrica é o nosso verso de dez sílabas, enquanto outros, em bem menor número, preferem o verso de doze sílabas, com o alegado objetivo de melhor preservar o texto, uma vez que as características morfológicas, sintáticas e lexicais da língua

\footnotetext{
${ }^{5}$ Não estão sendo considerados nesse cômputo os textos apresentados como adaptações ou recriações de qualquer tipo, nem aqueles feitos para montagens teatrais que não chegaram a ser publicados.
} 
portuguesa, bem como o seu caráter silábico, demandam mais espaço. A partir da segunda metade da década de 2010, surgiu uma nova tendência: a combinação de versos decassílabos e dodecassílabos, adotada por três tradutores desde então, como José Francisco Botelho.

(c) Há também a questão da linguagem: o tradutor pode se situar em diferentes pontos de um eixo cujos polos são, de um lado, linguagem elevada, com sintaxe elaborada, recorrendo a muitas inversões, vocabulário erudito e tratamento formal, empregando os pronomes "tu" e "vós" para traduzir thou e you; e de outro, uma linguagem despojada, com sintaxe predominantemente linear, e atualizações para o português contemporâneo, escrito ou falado, em que figuram, por exemplo, as formas de tratamento "você" e "o senhor/a senhora"; a associação de você, que leva a conjugação do verbo para a terceira pessoa, com pronomes oblíquos e possessivos de segunda pessoa; e a flutuação entre a conjugação do imperativo na segunda ou na terceira pessoa do singular (mesmo quando o tratamento se dá na terceira pessoa), caracterizando, assim, uma fala mais coloquial. As traduções de Carlos Alberto Nunes situam-se próximas ao extremo do primeiro polo mencionado, enquanto as de Millôr praticamente inauguraram a tendência na direção oposta.

(d) Outro aspecto que pode distinguir as traduções entre si é a sua orientação, no sentido de optar por serem mais voltadas para o palco, como as de Millôr Fernandes, quando a preocupação com a encenabilidade e a falabilidade será uma das principais balizas para as escolhas feitas e as soluções adotadas, ou mais voltadas para a página, direcionadas a um público alvo de leitores, teoricamente com tempo e disposição para se deter em notas de rodapé esclarecedoras, consultar dicionários e navegar entre as diferentes seções do texto para ajudar na leitura, entre outras funcionalidades que a materialidade do texto proporciona. Mas é importante lembrar que não são posições excludentes: há traduções profusamente comentadas que atentam igualmente para o seu potencial de encenação, sendo José Roberto O'Shea um exemplo eloquente de tradutor com esse duplo compromisso. 
(e) As diferenças na apresentação da edição também são dignas de nota. A maioria das traduções não vem acompanhada do original, mas há algumas edições bilíngues, com o original na página da esquerda e o português espelhado, à direita, e também traduções interlineares, como as da editora Movimento, com o inglês e o português se alternando na página. E há, ainda, edições com aparato crítico, como prefácios, textos complementares e notas, e outras que trazem apenas o texto da peça.

(f) Também cabe mencionar o texto-base usado para a tradução. Não só existem peças com mais de um texto de autoridade - característica da produção shakespeariana, como já mencionado - como também as diferentes edições em inglês têm seus respectivos responsáveis pela fixação dos textos, o que inclui decisões relativas à pontuação, por exemplo, ou à escolha de uma palavra específica quando há dúvida entre duas parecidas, mas com significados distintos. É o caso, por exemplo, da variação, no primeiro solilóquio do personagem Hamlet (I.ii), entre solid flesh (carne sólida), ou sullied flesh (carne impura, maculada).

(g) Por fim, um outro fator que contribui para as diferenças entre as traduções, sobretudo no eixo diacrônico, é o avanço dos estudos shakespearianos, que pode rever ou complexificar o sentido de determinados termos e expressões, ressignificar determinadas passagens e questões históricas e culturais, ou ainda inscrever, nas obras, novas interpretações, a partir de teorias e abordagens mais contemporâneas. As traduções mais recentes, portanto, se beneficiam dessa massa crítica cada vez mais robusta.

Todas essas diferenças só fazem acentuar a riqueza do repertório resultante, por oxigenar as obras originárias e permitir que cada leitor busque, entre tantas (re)traduções, aquela que melhor irá atender às suas expectativas com relação ao autor e às peças. Em relação às retraduções stricto sensu, entendidas como toda tradução feita depois da primeira tradução de uma obra, enquanto as traduções das diferentes peças de Shakespeare foram inauguradas em 1933 com o Hamlet pioneiro de Tristão da Cunha, como já mencionado, as retraduções começaram na década de 1940, quando um segundo Romeu e 
Julieta em português do Brasil foi publicado em 1948, seguindo-se ao primeiro, por Onestaldo de Pennafort, em 1940. Com a publicação da tradução de 37 peças por Carlos Alberto Nunes, ao longo dos anos 1950, todas as demais traduções feitas a partir de então constituem, tecnicamente, retraduções, salvo no caso das duas peças recentemente incorporadas ao cânone, Edward III e The Two Noble Kinsmen, cujas primeiras transposições para o português do Brasil foram realizadas já no século atual. Ao se analisar o conjunto formado pelas traduções e retraduções das peças de Shakespeare no Brasil publicadas ao longo de quase nove décadas, algumas considerações de caráter geral podem ser feitas, das quais destaco três, que apresento a seguir.

A primeira delas diz respeito à seguinte questão: essas traduções representaram uma força conservadora ou inovadora em relação à conjuntura estética e política em que foram produzidas? 0 que se percebe, de modo geral, é que as traduções têm um viés conservador, na medida em que, de um lado, não procuraram introduzir mudanças na literatura ou na poesia do contexto de recepção (ou seja, não é pela via da tradução de textos shakespearianos que novos gêneros ou estilos vêm sendo introduzidos no sistema literário brasileiro). E de outro lado, também não se arriscaram a ensaiar experiências com poéticas tipicamente brasileiras, numa proposta antropofágica de hibridizar Shakespeare.

Em relação especificamente às traduções versificadas, é possível perceber que, enquanto prevaleceu no Brasil a tendência de haver poéticas dominantes, até mais ou menos a década de 1980, as traduções shakespearianas pouco recorreram às formas e métricas mais identificadas com cada período. Na década de 1930, associada à segunda fase do movimento modernista, em que a poesia brasileira se caracterizou pela liberdade formal, sem preocupação com métrica ou rima, a primeira tradução shakespeariana em prosa e verso o Romeu e Julieta de Onestaldo de Pennafort - foi realizada em métrica decassilábica e rimas impecáveis, com a sintaxe direta servindo de contraponto à dicção elaborada. ${ }^{6}$

\footnotetext{
${ }^{6}$ Para conhecer mais detalhes sobre as diferentes traduções, consultar o portal Escolha seu Shakespeare (http://www.dbd.puc-rio.br/shakespeare/index.htm), que contém uma base de dados sobre as traduções de textos integrais do cânone dramático shakespeariano feitas para o
} 
Em contrapartida, nos anos 1940 e 50, em que predominou no Brasil a agenda estética da Geração de 45 , pode-se dizer que o estilo das 39 primeiras traduções e cinco retraduções shakespearianas correspondeu ao fazer poético do período, emulando o rigor formal e as formas fixas dos parnasianos.

Já na década de 1960, a maior inovação na nossa poesia foi o movimento concretista, surgido no final dos anos 1950, que dava por encerrado o ciclo histórico do verso como unidade rítmico-formal, exacerbado nas propostas poéticas dos Novíssimos, e buscava, em vez disso, explorar as camadas materiais do significante. Como analisa Paulo Britto,

[o]s poetas concretistas não se limitaram a abolir o metro e a rima: eles decretaram sumariamente a morte do verso como unidade do discurso poético; doravante a poesia seria mais que tudo uma forma de arte visual, retomando os avanços de Mallarmé e Ezra Pound heróis do movimento, vistos como concretistas avant la lettre. (2013: 4)

No entanto, as quatro traduções da poesia dramática shakespeariana produzidas em verso nessa década - de um total de 43 retraduções, considerando as 37 peças do cânone completo transpostas para o português por F. Carlos de Almeida Cunha Medeiros e Oscar Mendes - não abraçaram essa poética, preferindo adotar modelos textuais do parnasianismo, empregando decassílabos brancos e rimados conforme a distribuição do original. Talvez 0 estatuto de "clássico" associado a Shakespeare tenha tido - ou talvez ainda tenha - o poder de inibir eventuais inovações formais inspiradas no repertório vanguardista brasileiro.

Nos anos 1970, uma década sombria na vida política do país, as manifestações culturais continuavam controladas, restritas e abafadas, em decorrência das medidas políticas restritivas vigentes desde o final do decênio anterior. Na poesia, começava-se a buscar novos caminhos como alternativa às vanguardas de 1950-60, que agora viviam uma fase mais madura e, talvez, mais acomodada, já devidamente consagradas pela cultura nacional. Segundo Bosi (1994), uma das novas tendências identificadas foi o ressurgimento do verso, livre ou metrificado, em oposição à sintaxe ostensivamente gráfica dos

português do Brasil e publicadas sob forma de livro. Cada tradução é alvo de uma descrição que inclui as principais características da tradução e da edição, entre outras informações. 
concretos. E em contraposição a uma poesia bipolarizada, dividida, até pouco antes, entre a ênfase ideológica e a vanguarda formal, surge a poesia chamada "marginal", feita por pessoas que não pertenciam a círculos da intelectualidade e caracterizada por uma lírica em que predomina a expressão do eu, com uma dicção mais coloquial, trabalhando quase sempre com alguma variedade de verso livre. Nessa década, foram publicadas apenas duas retraduções de peças de Shakespeare, ambas em prosa, e nenhuma primeira tradução. Uma delas, o Rei Lear de Maryland Moraes (1972), empregou dicção antiquada para a época e sintaxe rebuscada ${ }^{7}$, enquanto Amansando Catarina, por Newton Belleza (1977), apresentou feição oposta, com dicção contemporânea e sintaxe linear, mas mantendo o uso de tu e vós, como é bastante comum até hoje.

A partir dos anos 1980, o ecletismo entrou em cena; na poesia, abriu-se espaço para os mais diferentes estilos, sem o predomínio de uma poética específica. Nesse campo, assim como na literatura, assumiu-se uma estética caracterizada como pós-moderna, onde a substituição regular de um cânone por outro, de um centro por outro, deu lugar a diversos cânones e diversos centros. Nesse momento avesso a generalizações, uma das poucas afirmações que se pode fazer é que começou a ser abolido o fosso que separava distintamente o português escrito do falado, levando à consequente valorização do registro coloquial e ao fenômeno da língua oral, em oposição às preocupações prescritivas da gramática tradicional, refletidas na chamada norma culta.

As traduções shakespearianas, acompanhando a tendência, se tornaram mais coloquiais e passaram a reproduzir mais explicitamente as obscenidades e o palavreado chulo do texto em inglês. Examinando-se, por exemplo, traduções diferentes de certas passagens de Hamlet, como o diálogo rude entre o príncipe e Ofélia pouco antes da representação da peça-dentro-da-peça (The Murder of Gonzago) pelos atores ambulantes (III.ii), ou a discussão entre ele e a mãe, Gertrudes, na cena da alcova (III.iv), percebe-se que um novo padrão de linguagem mais crua em português foi estabelecido nas traduções feitas a partir

\footnotetext{
${ }^{7}$ A título de ilustração, podemos citar: "mofino maricas", "petulante virago" (em falas de Petrúquio); “Afasta-te, peralvilho" (frase de Grêmio); “[...] não dardejes escárnio desses olhos" (frase de Catarina).
} 
dos anos 1980. É lícito supor que o término da censura rígida e a liberalização dos costumes também tiveram uma participação nessa mudança. Um outro tabu a cair por terra foi o que impedia o uso, na língua escrita, da combinação coloquial da forma de tratamento você com o pronome oblíquo de segunda pessoa te e o possessivo teu/tua, como já observado.

Nos anos 1990, surgiram novos e bons poetas em todo país, configurando uma confluência de gerações que se puseram em diálogo, numa via de mão dupla, de troca mútua e sem hierarquia (FerRAz 2011: 12). A própria linha editorial da coleção Claro Enigma, que surgiu na virada da década, já apontava para uma variedade de dicções, contemplando inclusive a revalorização do verso, seja em sua feição mais convencional, seja nas mais experimentais (FerRaz 2011: 13-14). Dentre as 26 retraduções publicadas na década, 18 foram em prosa e versos decassílabos, conjugando rigor formal e linguagem acessível e distensa. 0 renovado interesse por publicar obras de Shakespeare pode ser atribuído a fatores como a crescente ênfase das editoras em livros de bolso, mais baratos e acessíveis, e a uma espécie de apoteose do chamado Bardo no mundo inteiro e também no Brasil, extrapolando fronteiras disciplinares. Tradicionalmente admirados e estudados nos meios acadêmicos, os textos shakespearianos começaram a se disseminar no ambiente empresarial, que vem percebendo seu potencial de contribuição para o ensino de economia, direito, psicologia e política, entre outros campos.

Chegamos então ao século $\mathrm{XXI}$, quando as (re)traduções do teatro shakespeariano tiveram um grande impulso. Desde o início do novo milênio, como descreve Britto (2013: 11),

os poetas já não integram seitas literárias que se excomungam mutuamente. A agressiva rivalidade entre concretistas, neoconcretistas, praxistas e defensores da poesia participante só volta à tona hoje em dia quando representantes desses movimentos, agora na faixa dos setenta e muito ou oitenta anos, são entrevistados por suplementos literários. Os poetas mais jovens sentem-se livres para lançar mão dos repertórios técnicos deste ou daquele movimento histórico[.]

A multiplicidade, portanto, é uma das principais características da literatura e poesia brasileiras nesses últimos anos, em que não há um estilo dominante. Dessa forma, as 45 retraduções em prosa e verso publicadas desde 
a virada do século 8 parecem acomodar-se confortavelmente com suas formas fixas em meio à heterogeneidade legitimada da poesia contemporânea brasileira. A maioria delas empregou decassílabos, salvo duas que preferiram a métrica mais longa dos dodecassílabos, e outras cinco que adotaram uma combinação de versos de dez e de doze sílabas.

Em 2010, pela primeira vez desde o final da década de 1950, quando se completou a publicação do teatro completo traduzido por Carlos Alberto Nunes, surgiu uma nova primeira tradução, o Eduardo III em prosa de Elvio Funck, responsável também pela mais recente primeira tradução de mais uma peça, Os dois nobres parentes, igualmente em prosa, lançada em 2016 e também assinada por Funck. Todas as demais publicações foram retraduções: na década de 2000, 38 retraduções, sendo 21 em prosa e verso, e na de 2010, 45 retraduções, das quais novamente 21 reproduzindo a combinação original de prosa e verso.

A segunda consideração a ser feita com relação às traduções e retraduções publicadas é que raramente há uma agenda política explícita por trás da escolha da peça a traduzir ou da estratégia tradutória empregada. 0 único caso identificado por estudiosos da tradução até agora foi o Júlio César de Carlos Lacerda, objeto de artigos de John Milton e Eliane Euzebio (2004). Lacerda, importante jornalista e político brasileiro, foi um grande opositor de Getúlio Vargas, ex-ditador eleito pelo voto direto em 1950. O atentado a bala que Lacerda sofreu, em agosto de 1954, na porta do prédio onde residia, no Rio de Janeiro, no qual o seu segurança foi mortalmente atingido, desencadeou uma crise política que levou ao suicídio de Vargas, 19 dias depois, em 24 de agosto.

Em 1955, Lacerda traduziu o Júlio César de Shakespeare (publicado em 1965) motivado, segundo ele, pela analogia percebida entre a sua situação e a de Brutus na peça romana: por uma série de circunstâncias, analisadas nos artigos de Milton e Euzebio, Lacerda e Brutus perderam o estatuto de vítimas e passaram a ser vistos como vilões, causadores da morte dos dois governantes.

\footnotetext{
${ }^{8}$ Há uma relação das traduções publicadas por década, com suas respectivas opções formais, disponível na aba "links úteis" do portal Escolha seu Shakespeare (http://www.dbd.pucrio.br/shakespeare/links.html).
} 
Por fim, gostaria de chamar atenção para um fenômeno de certa forma relacionado às observações feitas acima: a redução no número de retraduções publicadas do teatro shakespeariano durante o período mais austero do governo militar (anos 1970), como ressaltei há pouco. Essa redução, na verdade, vai contra as expectativas, visto que diversas peças de Shakespeare - como, por exemplo, aquelas que versam sobre monarcas tirânicos - seriam bem propícias a traduções de resistência, como tem sido o caso em outros países sob regimes autoritários. Aparentemente, não se pode atribuir esse fato à censura rígida, visto que outros dramaturgos foram amplamente traduzidos com subtextos políticos durante o governo militar. O próprio Millôr Fernandes, conhecido por fazer oposição ao regime pela arma do humor e da sátira, usada principalmente por meio do folhetim $O$ Pasquim, não recorreu a Shakespeare para expressar sua insatisfação com o status quo, apesar de ter traduzido quatro peças do autor.

No cenário teatral, em contrapartida, houve nessa época adaptações de peças com objetivos políticos, naturalmente disfarçados, e que se repetiram na era Collor, já de forma nem um pouco disfarçada, até mesmo acentuada pelos textos dos programas das peças, por entrevistas dos diretores e atores, e em resenhas críticas. ${ }^{9}$

Finalizo aqui essas considerações a respeito da tradução no Brasil e da retradução de clássicos, com foco especial em Shakespeare, reiterando a importância de se ter um arco amplo de opções para quem quiser ler autores e obras canonizados em português, possibilitando que cada leitor em potencial identifique, dentre as diferentes reescritas, aquela(s) que mais corresponde(m) à imagem que construiu para si do autor e da obra. Essa diversidade, propiciada pela prática de retraduzir, corrobora o discurso da abundância de Berman

\footnotetext{
9 Para conhecer algumas dessas adaptações, consultar SMITH, C. B. O belo e o feio em cena e nos bastidores: duas montagens de Macbeth no Brasil turbulento de 1992. Tradução em Revista 14, p. 100-112, 2013; e AGUERO, D.A. Strange Images of Death: Violence and the Uncanny in Five Productions of Macbeth. 2009. Tese (Doutorado) - Programa de Pós-Graduação em Letras/Inglês e Literatura Correspondente. Universidade Federal de Santa Catarina, Florianópolis, 2009.
} 
(2017) e ainda provoca um oportuno efeito colateral, que é o surgimento de novos e instigantes objetos de pesquisa no âmbito dos Estudos da Tradução.

\section{Referências}

AQUINO, J. Conheça Index Translationum, o catálogo de livros traduzidos da UNESCO. Ecos da Tradução, 2017. Disponível em http://ecos-datraducao.blogspot.com/2017/09/conheca-index-translationum-ocatalogo.html. Acesso em 12 mar 2021.

Berman, A. A retradução como espaço da tradução. Trad. Clarissa Prado Marini e Marie-Hélène C. Torres. Cadernos de Tradução, v. 37, n. 2, Florianópolis, maio-agosto 2017, pp. 261-268.

Bosı, A. História Concisa da Literatura Brasileira. 35ª . ed. São Paulo: Cultrix, 1994.

BRITTO, P. H. A poesia brasileira hoje. 2013. Disponível em: http://www.letras.puc-

rio.br/media/filemanager/professores/paulo_britto/Poesia\%20brasilei ra\%20hoje.pdf. Acesso em 31 ago 2020.

Calvino, I. Por que ler os clássicos. Trad. Nilson Moulin. $2^{\mathrm{a}}$. ed., $4^{\mathrm{a}}$. reimpressão. São Paulo: Companhia das Letras, 1993.

Casanova, P. A República Mundial das Letras. Trad. Marina Appenzeller. São Paulo: Estação Liberdade, 2002.

Casanova, P. Translation as Unequal Exchange (Chapter 16). Tradução de Siobhan Brownlie. In: BAKER, Mona (ed.) Critical Readings in Translation Studies. London: Routledge, 2010: 285-303.

CBL - CÂmara Brasileira do LiVRo. FIPE CBL/SNEL - 13 anos Pesquisa Produção e Vendas do Setor Editorial Brasileiro, c2016. Disponível em http://cbl.org.br/downloads/fipe. Acesso em 25 fev 2021.

DIMENT, M. Why are so few translated books published in America? ALTA Language Services, 30 jun. 2019. Disponível em www.altalang.com/beyond-words/why-are-so-few-translated-bookspublished-in-america/. Acesso em 11 mar 2021.

EVEn-ZohaR, I. The Position of Translated Literature within the Literary Polysystem. Poetics Today, Vol. 11, No. 1, Polysystem Studies (Spring, 1990), pp. 45-51.

FerRAZ, P. A poesia brasileira na década de 1990. In: (org.) Roteiro da poesia brasileira: anos 90. São Paulo: Global, $2011:$ 7-19.

FIPE - FundaÇão Instituto de PesquISAs ECONÔMICAS. Relatório Produção e Vendas do Setor Editorial Brasileiro - Produto 2: Relatório sobre 2009. São Paulo: 
CBL, julho 2010. Disponível em http://cbl.org.br/downloads/fipe. Acesso em 25 fev 2021.

KoSKINEN, K.; PALOPOSKI, O. Retranslation. In: GAMBIER, Y.; VAN DOORSLAER, L. (eds.) Handbook of Translation Studies, vol. 1. Amsterdam: John Benjamins, 2010: 294-298

LefEVERE, A. Translation, Rewriting and the Manipulation of Literary Fame. London: Routledge, 1992.

MiLton, J.; EuzebIO, E. Tradução e (identidade) política: as adaptações de Monteiro Lobato e o Julio César de Carlos Lacerda. In: MARTINS, Marcia A. P. (org.) Visões e identidades de Shakespeare no Brasil. Rio de Janeiro: Lucerna, 2004: 81-99.

Snel - Sindicato Nacional dos Editores de Livros. Pesquisas. Rio de Janeiro, 2020. Disponível em https://snel.org.br/pesquisas/. Acesso em 22 fev 2021.

VENUTI, L. The Translator's Invisibility: A History of Translation. London: Routledge, 2008 (1a. edição em 1995).

VENUTI, L. Retranslations: The Creation of Value. In: Translation Changes Everything: Theory and Practice. London: Routledge, 2013: 96-108.

VenUtI, L. Translation, Publishing, and World Literature: J.V. Foix's Daybook 1918 and the Strangeness of Minority. Translation Review, 95:1, 2016, pp. 8-24.

WYLER, L. Línguas, poetas e bacharéis. Rio de Janeiro: Rocco, 2003. 